\title{
A Novel Spectrophotometric Method for Determination of Gabapentin in Pharmaceutical Formulations Using 2,5-Dihydroxybenzaldehyde
}

\author{
Magda S. Saleh, Ahmed K. Youssef, Elham Y. Hashem*, Doaa A. Abdel-Kader \\ Chemistry Department, Faculty of Science, Assiut University, Assiut, Egypt \\ Email: elham hashem@yahoo.com
}

Received 22 February 2014; revised 30 March 2014; accepted 8 April 2014

Copyright (C) 2014 by authors and Scientific Research Publishing Inc.

This work is licensed under the Creative Commons Attribution International License (CC BY). http://creativecommons.org/licenses/by/4.0/

\section{Abstract}

A highly simple, rapid, sensitive and selective method is developed for spectrophotometric determination of gabapentin in pure form as well as in pharmaceutical formulations. The method is based on the formation of a yellow Schiff base derived from the condensation of gabapentin drug (1-amino methyl) cyclo hexane acetic acid and 2,5-dihydroxybenzaldehyde (DHBA) exhibiting a maximum absorbance at $445 \mathrm{~nm}$. The composition, molar absorptivity and effect of different excipient have been determined spectrophotometrically. Under optimized experimental conditions, Beer's law is obeyed in the concentration range $2.57-37.25 \mu \mathrm{g} / \mathrm{ml}$. The method is validated with respect to accuracy, precision, limit of detection and limit of quantification. The Sandell sensitivity, correlation coefficient and regression equation are calculated. The equilibrium constant and free energy change using Benesi-Hildebrand plot are also determined. The Schiff base derived from condensation of gabapentin with DHBA is also synthesized and characterized. The condensation reaction mechanism has been proposed.

\section{Keywords}

Gabapentin, 2,5-Dihydroxybenzaldehyde, Pharmaceutical Formulations, Spectrophotometric Analysis

\section{Introduction}

Gabapentin (GBP) (1-(aminomethyl) cyclohexane acetic acid) is a new antiepileptic drug which is a structural "Corresponding author.

How to cite this paper: Saleh, M.S., Youssef, A.K., Hashem, E.Y. and Abdel-Kader, D.A. (2014) A Novel Spectrophotometric Method for Determination of Gabapentin in Pharmaceutical Formulations Using 2,5-Dihydroxybenzaldehyde. Computational Chemistry, 2, 22-30. http://dx.doi.org/10.4236/cc.2014.22004 
analogue of neurotransmitter $\gamma$-aminobutyric acid (GABA). GBP, unlike GABA, has a cyclohexane molecule system and is able to penetrate through blood-brain barrier. GBP is used for the treatment of partial onset seizures with or without secondary generalized tonic-clonic convulsions in clinical practice [1] [2]. The reported analytical methods for GBP determination include high performance liquid chromatography (HPLC) [3]-[14], spectrofluorometry [15] [16], gas chromatography [17]-[19]. Despite that the spectrophotometric techniques had been commonly applied for the determination of some other drugs [20], only few spectrophotometric methods were reported in literature for determination of GBP, based on the reaction of the primary amino group of GBP with ninhydrine reagent in organic solvent medium [21]-[23]. And other spectrophotometric methods involve the determination of GBP via formation of charge-transfer complexes with $\pi$-acceptors in pharmaceutical formulations [24]-[26].

There is no spectrophotometric method till now for determination of gabapentin in pharmaceutical formulations through formation of Schiff base with DHBA. Our present study was simple, accurate and sensitive spectrophotometric procedure for determination of GBP in pharmaceutical formulations. The method was based on the reaction of primary amino group of GBP drug with DHBA at elevated temperature to produce Schiff base. No interference was observed in the assay of GBP from common excipients. The reaction conditions and application of the method for determination of GBP in pharmaceutical formulation have been established. In addition, the stoichiometric ratio of reactants, the equilibrium constant $(\mathrm{Kc})$ and free energy change $(\Delta \mathrm{G})$ were determined.

\section{Experimental Work}

\subsection{Materials}

All solutions were prepared from analytical grade materials with pure ethanol 99.8\% (Riedel-de Haen Germany). Gabapentin (GBP) pure was purchased from Sigma-Aldrich Co. (St. Louis, MO, USA). 2,5-dihydroxybenzaldehyde (DHBA) reagent was obtained from Alfa Aesor GmbH \& Co KG (Zeppelinstra Be Karl Sruche, Germany). Pharmaceutical formulations of GBP such as Gabtin capsules-100 mg (Al-Debeiky pharmaceutical products for Delta pharma, Egypt), and Conventin capsules $100 \mathrm{mg}$ (EVA PHARMA-Egypt) were purchased from local pharmacy.

A stock solution of $5.8 \times 10^{-3} \mathrm{M}$ GBP was prepared by dissolving the accurately weighed amount of the pure GBP in ethanol. Dilute solutions were obtained by accurate dilution. A $5.8 \times 10^{-3} \mathrm{M}$ solution of DHBA was prepared by dissolving the required amount of the reagent (DHBA) in ethanol.

\subsection{Instrumentation}

An evolution 300 UV-Vis. Spectrophotometer with $1.0 \mathrm{~cm}$ matched cells fitted with vision pro software of Thermo Election corporation (Cambridge, U.K.) was used for electronic spectral measurements. To obtain $\mathrm{pH}$ readings throughout the experimentation, a microprocessor $\mathrm{pH}$ meter (HANNA HI 211) was used.

\subsection{General Procedure and Construction of Calibration Graphs}

Different aliquots of GBP solution were transferred into test tubes. To each test tube $3 \mathrm{ml}$ of DHBA $\left(2 \times 10^{-3} \mathrm{M}\right)$ reagent in ethanol and $2 \mathrm{ml}$ ethanol were added, then test tubes were heated on a water-bath at $75 \pm 0.15^{\circ} \mathrm{C}$ for $15 \mathrm{~min}$. These solutions were transferred to volumetric flasks after cooling and the volume was made up to the mark with ethanol to provide final concentration range of $2-50 \mu \mathrm{g} \cdot \mathrm{ml}^{-1}$.

The absorbance of the solution was measured against a reagent blank at $445 \mathrm{~nm}$. The calibration graph was prepared by plotting absorbance versus concentration of gabapentin.

\subsection{Analysis of Pharmaceutical Formulations}

Twenty capsules of each formulation were accurately weighed and powdered in glass mortar. The quantity of the powder equivalent $10 \mathrm{mg}$ of gabapentin was dissolved in $100 \mathrm{ml}$ ethyl alcohol.

The procedure was continued as described in the general procedure. The amount of GBP present in capsule sample solution was determined by fitting the responses into the regression equation. 


\subsection{Interference from Excipients}

Samples were prepared by mixing $10 \mathrm{mg}$ of gabapentin with various amounts of common excipients such as cellulose, lactose, glucose, vitamin $\mathrm{C}$, starch and purified talc. The procedure was continued as mentioned above in the general procedure.

\section{Results and Discution}

\subsection{Spectral Characteristics}

Gabapentin (GBP) showed weak absorption band in UV range [21]. UV-spectrophotometric methods is not enough for the determination of GBP in pharmaceutical formulations. Attachment of chromophoric group to GBP increases the sensitivity of its detection. For this reason, DHBA was chosen as a chromagenic reagent. Ninhydrin reagent was used for the determination of an aliphatic primary amine [27]-[29].

The reaction is usually carried out by heating for a short time in an organic solvent and the reaction product is measured in the visible region depending on the reaction conditions [30].

\subsection{Reaction Mechanism}

Shiff bases derived from the condensation of aromatic aldehyde derivatives and aromatic primary amine were synthesized and characterized [31].

The reaction of GBP with DHBA was studied in ethanol media in the temperature range $45^{\circ} \mathrm{C}-80^{\circ} \mathrm{C}$. The visible absorption spectra of solutions were recorded in presence of excess reagent and spectra reflect the formation of yellow product with $\lambda_{\max }=445 \mathrm{~nm}$ at $\mathrm{T}=75 \pm 0.15^{\circ} \mathrm{C}$. Gabapentin interacts with DHBA reagent in ethanol medium at elevated temperature via oxidative deamination of the primary amino group followed by the condensation of the reduced DHBA to form the yellow colored Schiff base as represented by the Scheme 1 .

The absorption spectra of gabapentin, DHBA reagent and their reaction product are shown in Figure 1.

\subsection{Optimization of Reaction Conditions}

The reaction conditions were optimized. The number of parameters such as temperature, time, reagent concentration and solvent were investigated. The optimum conditions were established by changing one variable and observing its effect on the absorbance of the colored product.

\subsection{Effect of Solvents}

Different solvents such as water, ethanol, methanol, isopropanol, dioxane and acetonitrile have been tested, but the best results were obtained with ethanol.

\subsection{The Effect of Concentration of DHBA}

The effect of the volume of DHBA $(80.04 \mu \mathrm{g} / \mathrm{ml})$ on the absorbance of the colored product was studied in ethanol medium in the range of $1.0-7.0 \mathrm{ml}$ at $70^{\circ} \mathrm{C}$. The absorbance increases with the increase in the volume of DHBA became constant at $6.0 \mathrm{ml}$. Further addition of DHBA did not cause change in absorbance and therefore $48.024 \mu \mathrm{g} / \mathrm{ml}$ DHBA was chosen as an optimum value (Figure 2(a)).

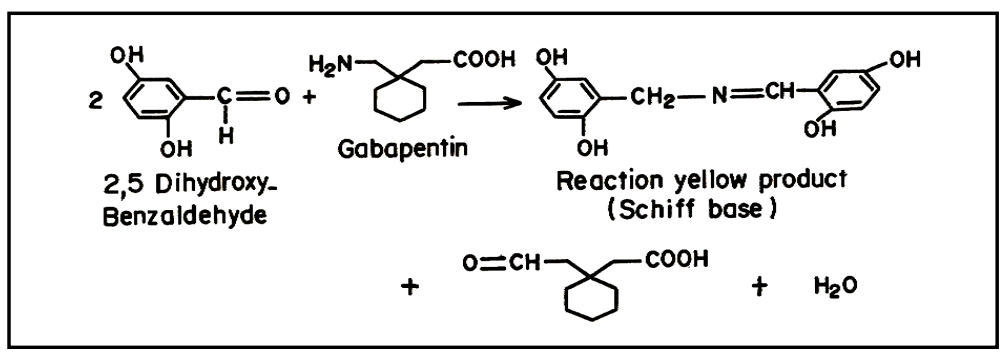

Scheme 1. Suggested reaction pathway between 2,5-Dihydroxy benzaldehyde (DHBA) and Gabapentin. 


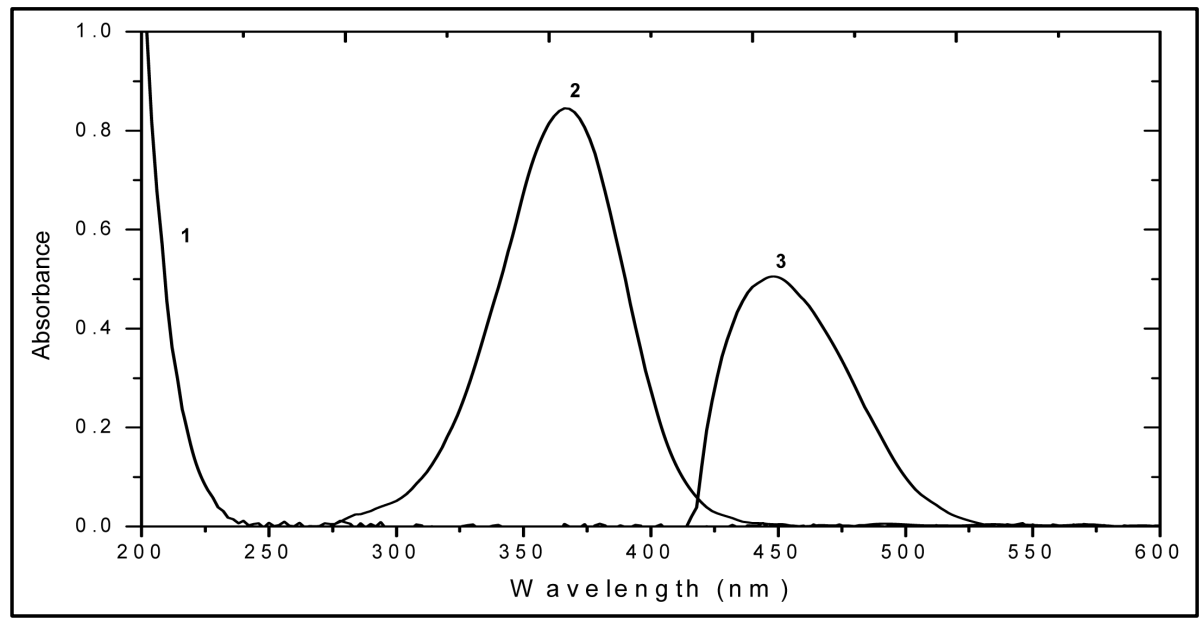

Figure 1. Absorption spectra of (1) $2.9 \times 10^{-4} \mathrm{M}$ GBP in ethanol, (2) $6.0 \times 10^{-4} \mathrm{M}$ DHBA reagent in ethanol and (3) GBP-DHBA reaction product, $\left(\mathrm{C}_{\mathrm{GBP}}=2.9 \times 10^{-4}, \mathrm{C}_{\mathrm{DHBA}}=6.0 \times\right.$ $\left.10^{-4} \mathrm{M}\right)$. In ethanol at $\mathrm{T}=75 \pm 0.15^{\circ} \mathrm{C}$.

\subsection{The Effect of Temperature}

The effect of temperature on the absorbance of the reaction product was studied in ethanol medium in the range $\left(45^{\circ} \mathrm{C}-80^{\circ} \mathrm{C}\right)$, keeping the constant concentration of GBP $(14.898 \mu \mathrm{g} / \mathrm{ml})$ and $(24.012 \mu \mathrm{g} / \mathrm{ml}) \mathrm{DHBA}$. The maximum absorbance was obtained at $75^{\circ} \mathrm{C} \pm 0.15^{\circ} \mathrm{C}$ (Figure 2(b)).

\subsection{The Influence of Time}

The reaction time was determined by following the absorbance of the developed Schiff base in ethanol medium at $75^{\circ} \mathrm{C}$ at different time intervals. Complete color development was attained after 15 min (Figure 2(c)).

\subsection{Stoichiometry of the Reaction}

The Stoichiometry of the GBP-DHBA Schiff base was further verified by the method of continuous variation [32]. In solution with $\mathrm{C}_{\mathrm{T}}=\mathrm{C}_{\mathrm{G}}+\mathrm{C}_{\mathrm{DHBA}}=3.48 \times 10^{-4} \mathrm{~mol} \cdot \mathrm{L}^{-1}$ at $75^{\circ} \mathrm{C}$, the maximum of the Jop's plot corresponds to a component ratio of 1:2 (GBP:DHBA).

\subsection{Equilibrium Constant and Free Energy Change}

The equilibrium Constant was determined for the interaction of gabapentin drug with DHBA reagent using Benesi-Hildebrand equation [33].

$$
\mathrm{C}_{\mathrm{a}} / \mathrm{A}=1 / \varepsilon+1 / \varepsilon \mathrm{K}_{\mathrm{c}} \cdot 1 / \mathrm{C}_{\mathrm{g}}
$$

where $\mathrm{C}_{\mathrm{a}}$ and $\mathrm{C}_{\mathrm{g}}$ are the concentration of the aldehyde reagent and GBP drug respectively. A is the absorbance, $\varepsilon$ is the molar absorptivity and $\mathrm{K}_{\mathrm{c}}$ is the equilibrium Constant of GBP-DHBA Schiff base. The free energy change of reaction product $(\Delta \mathrm{G})$ was calculated from the equilibrium constant by the following equation [34].

$$
\Delta \mathrm{G}=-2.303 \mathrm{RT} \times \log \mathrm{K}_{\mathrm{c}}
$$

where $\Delta \mathrm{G}$ is the free energy change of the Schiff base $\left(\mathrm{K} \cdot \mathrm{cal} \cdot \mathrm{mol}^{-1}\right), \mathrm{R}$ is the gas constant $(0.001987$ $\left.\mathrm{K} \cdot \mathrm{cal} \cdot \mathrm{mol}^{-1} \cdot \mathrm{deg}^{-1}\right)$, $\mathrm{T}$ the temperature in Kelvin $\left(273+\mathrm{C}^{0}\right)$ and $\mathrm{K}_{\mathrm{c}}$ is the equilibrium Constant of drug-DHBA reaction product.

The calculated values of equilibrium Constant $\mathrm{K}_{\mathrm{c}}$ and free energy change of GBP-DHBA Schiff base were found to be $4.593 \times 10^{3}$ and $-5.832 \mathrm{~K} \cdot \mathrm{cal} \cdot \mathrm{mol}^{-1}$ respectively.

\subsection{Construction of the Calibration Curve and Statistical Analysis}

Under the optimum experimental conditions, the standard calibration curve (Figure 3) for the proposed method 

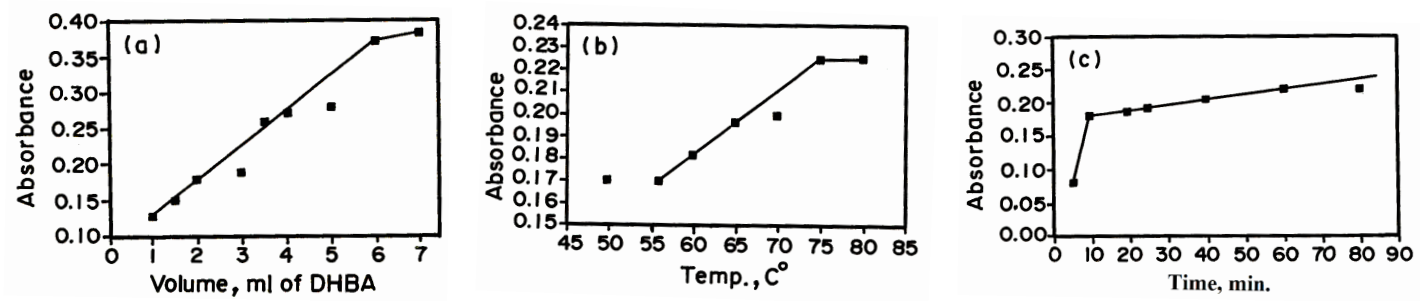

Figure 2. Reaction condition of the color formation of GBP-DHBA reaction product. (a) Effect of DHBA (by volume), GBP: $29.796 \mu \mathrm{g} \cdot \mathrm{ml}^{-1}, \mathrm{~T}=70^{\circ} \mathrm{C}$; (b) Effect of temperature, GBP: $14.898 \mu \mathrm{g} \cdot \mathrm{ml}^{-1}$, DHBA: 24.012 $\mathrm{g} \cdot \mathrm{ml}^{-1}$; (c) Effect of time, GBP: $14.898 \mu \mathrm{g} \cdot \mathrm{ml}^{-1}$, DHBA: $24.012 \mu \mathrm{g} \cdot \mathrm{ml}^{-1}, \mathrm{~T}=75^{\circ} \mathrm{C}$.

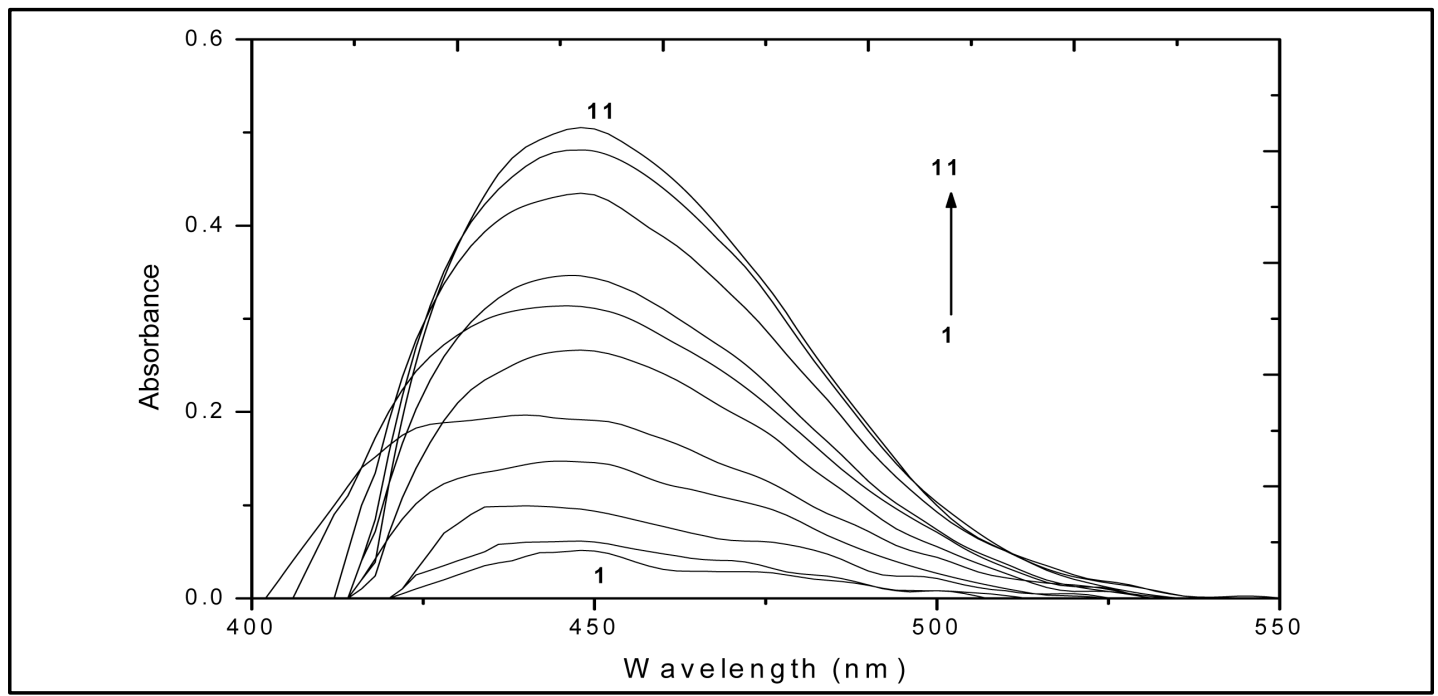

Figure 3. Absorption spectra of GBP-DHBA reaction product, GBP concentration range from 2.483 (1) to 49.66 $\mu \mathrm{g} \cdot \mathrm{ml}^{-1}(11)$ with regular successive additions in presence of $6.0 \times 10^{-4} \mathrm{M}$ DHBA reagent in ethanol at $\mathrm{T}=75 \pm$ $15^{\circ} \mathrm{C}$.

obeyed Beer's law over the concentration range of $2.57-37.25 \mu \mathrm{g} / \mathrm{ml}$ at $\lambda_{\max }=445 \mathrm{~nm}$. It was found that the absorbance was stable for at least two days at room temperature. Linear regression analysis of calibration data gave the regression equation cited in Table 1, with correlation coefficient close to unity.

The within day precision assay was carried out through replicate analysis $(n=3)$ of gabapentin corresponding to $15,20,30 \mu \mathrm{g} / \mathrm{ml}$.

The interday precision was also evaluated through replicate analysis of the pure sample for three consecutive days at the same concentration levels as used in within day precision. The results of these assays are reported in Table 2.

As can be seen from Table 2 that recovery values for intraday and interday precision were in the range of $99.25 \%$ to $101.53 \%$ and RSD values for intraday and interday precision were in the range of $0.0057 \%$ to $0.018 \%$.

\subsection{Specificity}

The specificity of the method was investigated by observing any interference encountered from the excipients generally presented in pharmaceutical formulations. The good percentage recoveries were summarized in Table 3 revealed that no interference was observed from any of these excipients in the proposed method.

\subsection{Limit of Detection (LOD) and Limit of Quantification (LOQ)}

The LOD and LOQ were calculated for GBP-DHBA reaction product. The theoretically determined values of LOD and LOQ were cross checked by actual analysis of these concentrations using proposed method (Table 1). 
Table 1. Regression Analysis Data and summary of validation parameters for the proposed method.

\begin{tabular}{cc}
\hline Parameters & Gapabentin \\
$\lambda_{\max }, \mathrm{nm}$ & $445 \mathrm{~nm}$ \\
Beer's law limits $\left(\mu \mathrm{g} \cdot \mathrm{ml}^{-1}\right)$ & $2.57-37.25$ \\
Ringbom limits $\left(\mu \mathrm{g} \cdot \mathrm{ml}^{-1}\right)$ & $3.98-35.48$ \\
Molar absorptivity $\left(\mathrm{Lml}^{-1} \cdot \mathrm{cm}^{-1}\right)$ & $2.1022 \times 10^{3}$ \\
Sandell's sensitivity $\left(\mu \mathrm{g}^{-1} \mathrm{~cm}^{-1}\right)$ & 0.08145 \\
Regression equation A= a $\mathrm{b} \mathrm{X}$ & $\mathrm{A}=0.0025+0.01227 \mathrm{X}$ \\
Slope (b) & 0.01227 \\
Intercept (a) & 0.0025 \\
Correlation coefficient & 0.989 \\
Limit of detection (LOD), $\mu \mathrm{g} \cdot \mathrm{ml}^{-1}$ & 0.33 \\
Limit of quantification (LOQ), $\mu \mathrm{g} \cdot \mathrm{ml}^{-1}$ & 0.996 \\
\hline
\end{tabular}

Table 2. Summary of accuracy and precision results of the proposed method in pure form.

\begin{tabular}{|c|c|c|c|c|c|c|}
\hline \multirow{2}{*}{ Proposed method } & \multicolumn{2}{|c|}{ Amount $\left(\mu \mathrm{g} \cdot \mathrm{ml}^{-1}\right)$} & \multirow{2}{*}{ RSD \% } & \multirow{2}{*}{ Recovery \% } & \multirow{2}{*}{$\mathrm{SAE}^{\mathrm{b}}$} & \multirow{2}{*}{ C. $L^{\mathrm{c}}$} \\
\hline & Taken & Found $\pm \mathrm{SD}^{\mathrm{a}}$ & & & & \\
\hline Intraday assay & $\begin{array}{l}15 \\
20 \\
30\end{array}$ & $\begin{array}{l}15.23 \pm 0.0027 \\
19.85 \pm 0.0028 \\
30.09 \pm 0.0023\end{array}$ & $\begin{array}{c}0.018 \\
0.011 \\
0.0077\end{array}$ & $\begin{array}{l}101.53 \\
99.25 \\
100.3\end{array}$ & $\begin{array}{c}1.53 \\
0.75 \\
0.3\end{array}$ & $\begin{array}{l} \pm 3.35 \times 10^{-3} \\
\pm 3.48 \times 10^{-3} \\
\pm 2.86 \times 10^{-3}\end{array}$ \\
\hline Interday assay & $\begin{array}{l}15 \\
20 \\
30\end{array}$ & $\begin{array}{l}15.08 \pm 0.0021 \\
19.98 \pm 0.0072 \\
29.97 \pm 0.0072\end{array}$ & $\begin{array}{c}0.014 \\
0.0086 \\
0.0057\end{array}$ & $\begin{array}{c}100.53 \\
99.9 \\
99.9\end{array}$ & $\begin{array}{c}0.53 \\
0.1 \\
0.1\end{array}$ & $\begin{array}{l} \pm 2.57 \times 10^{-3} \\
\pm 2.14 \times 10^{-3} \\
\pm 2.14 \times 10^{-3}\end{array}$ \\
\hline
\end{tabular}

${ }^{\mathrm{a}}$ Mean for 3 independent analysis; ${ }^{\mathrm{b}} \mathrm{SAE}$, standard analytical error; ${ }^{\mathrm{c} C . L ., ~ c o n f i d e n c e ~ l i m i t ~ a t ~} 95 \%$ confidence level and 4 Degrees of Freedom $(t=$ 2.776).

\subsection{Applications}

The proposed spectrophotometric method was applied to the determination of gabapentin in pharmaceutical formulations (Gaptin and Conventin).

The results obtained from Table 3 suggested that the proposed method could be applied for the determination of gabapentin in its dosage forms without interference observed at concentration levels examined.

The excellent linearity of the calibration graphs was clearly evident by the values of the correlation coefficients and standard deviations as shown in Table 4.

\subsection{Infrared Spectra}

The I. R. spectra of gabapentin showed the expected doublet of primary $\mathrm{NH}_{2}$ group at 2857 and $2931 \mathrm{~cm}^{-1}$, C-N stretch at $1165 \mathrm{~cm}^{-1}$ and the carbonyl stretch of $\mathrm{COOH}$ group at $1615 \mathrm{~cm}^{-1} .2,5$-dihydroxybenzaldehyde exhibited broad band at $3277.4-3250 \mathrm{~cm}^{-1}$ owing to two $\mathrm{OH}$ groups and $\mathrm{C}=\mathrm{O}$ stretch of aldehyde group at 1652 $\mathrm{cm}^{-1}$.

The formation of the Schiff base was evidenced by comparing the I. R. spectra of GBP-DHBA reaction product with that of GBP and DHBA. It was found that the twin peaks of $\mathrm{NH}_{2}$ in GBP disappeared indicating that the primary amine has been changed to tertiary. Also the I.R. spectra of GBP-DHBA reaction product exhibits a strong band at $1622 \mathrm{~cm}^{-1}$ which is characteristic of the azomethin $\mathrm{HC}=\mathrm{N}$-group.

\section{Conclusion}

The proposed spectrophotometric method was found to be simple, selective, rapid and sensitive compared with other established spectrophotometric methods. The reagent utilized in the proposed method was cheep, readily available and the procedure did not involve any critical reaction conditions or tedious sample preparation. Moreover, the method was free from interference by common additives and excipients. Also this method required less time for analysis, provided better RSD and LOD and had a wide concentration range over the pre- 
Table 3. Recovery of gabapentin in presence of different excipients.

\begin{tabular}{cc}
\hline Excipients & Recovery \pm RSD \\
\hline Cellulose & $99.83 \pm 0.71$ \\
Lactose & $99.97 \pm 0.82$ \\
Carboxymethyl cellulose & $98.57 \pm 0.33$ \\
Glucose & $99.45 \pm 0.29$ \\
Vitamin C & $98.97 \pm 0.35$ \\
Starch & $99.55 \pm 0.88$ \\
Purified talc & $99.85 \pm 0.27$ \\
\hline
\end{tabular}

Table 4. Application of the proposed method to the determination of gabapentin drug in dosage forms.

\begin{tabular}{cccccc}
\hline Marketed formulation & Certified value $\left(\mu \mathrm{g} \cdot \mathrm{ml}^{-1}\right)$ & Found value $\left(\mu \mathrm{g} \cdot \mathrm{ml}^{-1}\right)$ & Relative error \% & recovery & RSD \\
\hline Gaptin $^{\mathrm{a}}$ & 377.41 & 375.01 & 0.64 & 99.36 & 0.0055 \\
Conventin $^{\mathrm{b}}$ & 248.29 & 252.75 & 1.79 & 100.016 & 0.0082 \\
\hline
\end{tabular}

${ }^{\mathrm{a}}$ Product of Al-Debeiky Pharmaceutical products for Delta Pharma-Egypt; ${ }^{\mathrm{b}}$ product of EVA Pharma-Egypt.

viously published methods [35] [36]. Hence, it could be concluded that the developed spectrophotometric method was accurate, precise, and selective and could be employed successfully for the estimation of gabapentin in pharmaceutical formulations. The excellent recoveries obtained showed no interference from the common excipients.

\section{References}

[1] Goa, K.L. and Sokrin, E.M. (1993) Gabapentin: A Review of Its Pharmacological Properties and Clinical Potential in Epilepsy. Drugs, 46, 409-427. http://dx.doi.org/10.2165/00003495-199346030-00007

[2] Etwes, R.D.C. and Binnie, C.D. (1996) Clinical Pharmacokinetics of the Newer Antiepileptic Drugs: Lamotrigine, Vigabatrin, Gabapentin and Oxcarbazepine. Clinical Pharmacokinetics, 30, 403-415. http://dx.doi.org/10.2165/00003088-199630060-00001

[3] Hengy, H. and Kolle, E.U. (1985) Determination of Gabapentin in Plasma and Urine by High-Performance Liquid Chromatography and Pre-Column Labelling for Ultraviolet Detection. Journal of Chromatography B: Biomedical Sciences and Applications, 341, 473-478. http://dx.doi.org/10.1016/S0378-4347(00)84064-5

[4] Juenke, J.M., Brown, P.L., Mc Millin, G.A. and Urry, F.M. (2003) Procedure for the Monitoring of Gabapentin with 2,4,6-Trinitrobenzene Sulphonic Acid Derivatizaiton Followed by HPLC with Ultraviolet Detection. Clinical Chemistry, 49, 1198-1201. http://dx.doi.org/10.1373/49.7.1198

[5] Wad, N. and Kramer, G. (1998) Sensitive High-Perfomance Liquid Chromatographic Method with Fluorometric Deterction for the Simultaneous Determination of Gabapentin and Vigabatrin in Serum and Urine. Journal of Chromatography B: Biomedical Sciences and Applications, 705, 154-158. http://dx.doi.org/10.1016/S0378-4347(97)00521-5

[6] Zhu, Z. and Neirinck, L. (2002) High-Performance Liquid Chromatographic Method for the Determination of Gabapentin in Human Plasma. Journal of Chromatography B: Biomedical Sciences and Applications, 779, 307-312.

[7] Forrest, G., Sills, G.J., Leach, J.P. and Brodie, M.J. (1996) Determination of Gabapentin in Plasma by High-Performance Liquid Chromatography. Journal of Chromatography B: Biomedical Sciences and Applications, 681, 421-425. http://dx.doi.org/10.1016/0378-4347(96)00074-6

[8] Juergens, U.H., May, T.W. and Rambeck, B. (1996) Simultaneous HPLC Determination of Vigabatrin and Gabapentin in Serum with Automated Pre-injection Derivatizaiton. Journal of Liquid Chromatography and Related Technology, 19 , 1459-1471. http://dx.doi.org/10.1080/10826079608007195

[9] Ratnaraj, N. and Patsalos, P.N. (1998) Simultaneous HPLC Determination of Vigabatrin and Gabapentin in Serum with Automated Pre-Injection Derivatizaiton. Therapeutic Drug Monitoring, 20, 430-434. http://dx.doi.org/10.1097/00007691-199808000-00013

[10] Jiang, Q. and Li, S. (1999) Rapid High-Performance Liquid Chromatographic Determination of Serum Gabapentin. Journal of Chromatography B: Biomedical Sciences and Applications, 727, 119-123. http://dx.doi.org/10.1016/S0378-4347(99)00027-4

[11] Tang, P.H., Miles, M.V., Glauser, T.A. and Grauw, T.D. (1999) Automated Microanalysis of Gabapentin in Human 
Serum by High-Performance Liquid Chromatography with Fluorometric Detection. Journal of Chromatography B: Biomedical Sciences and Applications, 727, 125-129. http://dx.doi.org/10.1016/S0378-4347(99)00077-8

[12] Chollet, D.F., Goumaz, L., Juliano, C. and Anderegg, G. (2000) Fast Isocratic High-Performance liquid Chroamatographic Assay Method for the Simultaneous Determination of Gabapentin and Vigabatrin in Human Serum. Journal of Chromatography B: Biomedical Sciences and Applications, 746, 311-314. http://dx.doi.org/10.1016/S0378-4347(00)00327-3

[13] Gauthier, J.D. and Gupta, R. (2002) Determination of Gabapentin in Plasma by Liquid Chromatography with Fluorescence Detection after Solid-Phase Extraction with $\mathrm{C}_{18}$ Column. Clinical Chemistry, 48, 2259-2261.

[14] Vermeij, T.A.C. and Edelbroek, P.M. (2004) Simultaneous High Performance Liquid Chromatographic Analysis of Pregabalin, Gabapentin and Vigabatrin in Human Serum by Precolumn Derivatization with O-phthaldialdehyde and Fluorescenc Detection. Journal of Chromatography B: Biomedical Sciences and Applications, 810, 297-303.

[15] Belal, F., Abdin, H., Al-Majed, A. and Khalil, N.Y. (2002) Spectrofluorimetric Determination of Vigabatrin and Gabapentin in Urine and Dosage Forms Through Derivatization with Fluorescamine. Journal of Pharmaceutical and Biomedical Analysis, 27, 253-260. http://dx.doi.org/10.1016/S0731-7085(01)00503-9

[16] Hassan, E.M., Belal, F., Al-Deeb, O.A. and Khalil, N.Y. (2001) Spectrofluorimetric Determination of Vigabatrin and Gabapentin in Dosage Forms and Spiked Plasma Samples through Derivatization with 4-Chloro-7-Nitrobenzo-2-Oxa-1,3-Diazole. Journal of AOAC International, 84, 1017-1024.

[17] Wolf, C.E., Saady, J.J. and Poklis, A. (1996) Determination of Gabapentin in Serum Using Solid-Phase Extraction and Gas-Liquid Chromatography. Journal of Analytical Toxicology, 20, 498-501. http://dx.doi.org/10.1093/jat/20.6.498

[18] Hooper, W.D., Kavanagh, M.C. and Dickinson, R.G. (1990) Determination of Gabapentin in Plasma and Urine by Capillary Column Gas Chromatography. Journal of Chromatography B: Biomedical Sciences and Applications, 529, 167-174. http://dx.doi.org/10.1016/S0378-4347(00)83818-9

[19] Kushnir, M.M., Crossett, J., Brown, P.I. and Urry, F.M. (1999) Analysis of Gabapentin in Serum and Plasma by SolidPhase Extraction and Gas-Chromatography-Mass Spectrometry for Therapeutic Drug Monitoring. Journal of Analytical Toxicology, 23, 1-6. http://dx.doi.org/10.1093/jat/23.1.1

[20] Hashem, E.Y. and Youssef, A.K. (2013) Spectrophotometric Determination of Norepinephrine with Sodium Iodate and Determination of Its Acidity Constants. Journal of Applied Spectroscopy, 80, 258-264. http://dx.doi.org/10.1007/s10812-013-9755-y

[21] Abdellatef, H.E. and Khalil, H.M. (2003) Colorimetric Determination of Gabapentin in Pharmaceutical Formulation. Journal of Pharmaceutical and Biomedical Analysis, 31, 209-214. http://dx.doi.org/10.1016/S0731-7085(02)00572-1

[22] Galande, V.R., Baheti, K.G. and Dehghan, M.H. (2010) UV-VIS Spectrophotometric Method for Estimation of Gabapentin and Methylcobalamin in Bulk and Tablet. International Journal of Chemical Technological Research, 2, 695699.

[23] Siddiqui, F.A., Arayne, M.S., Sultana, N., Qureshi, F., Mirza, A.Z., Zuberi, M.H., Bahadur, S.S., Afrdi, N.S., Shamshad, H. and Rehman, N. (2010) Spectrophotometric Determination of Gabapentin in Pharmaceutical Formulations Using Ninhydrin and $\pi$-Acceptors. European Journal of Medicinal Chemistry, 45, 2761-2767. http://dx.doi.org/10.1016/j.ejmech.2010.02.058

[24] Foster, R. (1969) Organic Charge Transfer Complexes. Academic Press, London.

[25] Melby, L.R. (1970) The Chemistry of the Cyano Group. Intersciences Publisher, John Wiley and Sons, New York.

[26] Rao, C.N.R., Bhat, S.N. and Dwedi, P.C. (1972) Spectroscopy of Electron Donor-Acceptor Systems. Applied Spectroscopic Reviews, 5, 1-170. http://dx.doi.org/10.1080/05704927208081699

[27] Rahman, N. and Azmi, S.N.H. (2001) Spectrophotometric Method for the Determination of Ambdipine Besylate with Ninhydrin in Drug Formaulations. Il Farmaco, 56, 731-735. http://dx.doi.org/10.1016/S0014-827X(01)01093-X

[28] Nobrega, J.D.A., Fatibello-Filho, O. and Vieira, I.D.C. (1994) Flow Injection Spectrophotometric Determination of Aspartame in Dietary Products. Analyst, 119, 2101-2104.

[29] Molnar-Perl, I. and Pinter-Szakacs, M. (1989) Spectrophotometric Determination of Tryptophan in Intact Proteins by the Acid Ninhydrin Method. Analytical Biochemistry, 177, 16-19. http://dx.doi.org/10.1016/0003-2697(89)90005-5

[30] Gorog, S. (1995) Ultraviolet-Visible Spectrophotometry in Pharmaceutical Analysis. CRC Press, New York.

[31] Osman, A.H., Saleh, M.S. and Mahmoud, S.M. (2004) Synthesis, Characterization, and Photochemical Studies of Some Copper Complexes of Schiffs Bases Derived from 3-Hydraziono-6-methyl[1,2,4]triazin-5(4H)one. Synthesis and Reactivity in Inorganic and Metal Organic Chemistry, 34, 1069-1085. http://dx.doi.org/10.1081/SIM-120039258

[32] Job, P. (1928) Formation and Stability of Inorganic Complexes in Solution. Ann. Chim., 9, 113-203.

[33] Benesi, H.A. and Hildebrand, J.H. (1949) A Spectrophotometric Investigation of Interaction of Iodine with Aromatic 
Hydrocarbons. Journal of the American Chemical Society, 71, 2703-2707. http://dx.doi.org/10.1021/ja01176a030

[34] Martin, A.N. and Swarbrick, J. (1969) Physical Pharmacy. 3rd Edition, Lee \& Febiger, New York.

[35] Gujral, R.S., Haque, S.M. and Shanker, P. (2009) A Sensitive UV Spectrophotometric Method for the Determination of Gabapentin. European Journal of Chemistry, 6, 163-170.

[36] Ambalal, P.S. and Natavarlal, P. (2011) Visible Spectrophotometric Methods for Determination of Gabapentin in Pharmaceutical Tablet and Capsule Dosage Forms. Asian Journal of Pharmacy and Life Science, 1, 239-249. 